\title{
PSYCHOLOGICAL WELL-BEING AMONG POSTGRADUATE STUDENTS
}

\author{
S. Roslan, N. Ahmad, N. Nabilla and Z. Ghiami \\ Faculty of Educational Studies, University Putra Malaysia, Serdang, Malaysia
}

\begin{abstract}
This study attempted to determine the level of psychological well-being among postgraduate students. The study also aimed to assess the relationship between psychological well-being and demographic factors, such as age and field of study. Psychological well-being questionnaires were administered to a sample of 192 Master of Education students. The findings demonstrated that Master of Education students possessed a slightly high level of psychological well-being. Differences were found in students' psychological well-being across age groups, $F(4,167)=3.178, p=0.01$, and field of study, $F(8,163)=$ $2.668, p=0.01$, respectively. According to the results, students in the age group of 41 years and above possessed the highest level of psychological well-being $(M=5, S D=0.71)$.
\end{abstract}

Key words: psychological well-being, age, field of study, postgraduate students

Corresponding author: Samsilah Roslan, MD, Faculty of Educational Studies, University Putra Malaysia, Serdang, Malaysia, phone: 019278 5705, e-mail: Samsilah@upm.edu.my

\section{INTRODUCTION}

T he conceptualization of the psychological wellbeing has been in the state of divergence ever since it was the first study. Some researchers have associated psychological well-being with the fulfillment of life potential and happiness [1], while others have associated well-being with personal experience of individuals [2] or with the result of accomplishing goals [3], as well as the feeling of pleasure from participating in fascinating activities [4]. According to Ryff et al. [5], psychological well-being refers to the extent to which people feel that they have meaningful control over their life and their activities. Nevertheless, psychological well-being problems have become increasingly common among university students nowadays, especially postgraduate students who are prone to psychological problems [6]. Researchers have shown that the poor psychological well-being appears to be a very crucial and critical issue among postgraduate students who are changing academic environments from a structured environment (course-taking) to a more unstructured environment (independent research). Lovitts et al. stated that postgraduate studies entail two different stages, dependent and independent [7]. The dependent stage would include the Master's degree stage, whereby students are required to take courses and conduct research projects under close supervision from their advisors, while the independent stage includes the doctorate degree whereby students are conducting creative and original work to contribute to the specialized body of knowledge. Nevertheless, for any of these stages or transitions, students need to deal with intellectual, social, and psychological transformations, as these transitions are also perceived as a process of maturation [7-9].

Therefore, postgraduate students often have to deal with challenges and problems that hinder the completion of their studies [9]. Moreover, they need to avoid any high stress which is becoming increasingly worrying, as it has been found that the number of 
psychological problems and their severity are on the rise among student population [10-12]. Hence, problems such as financial restrain [13], time constraints, which limit the time left to complete their assignment and research paper due to working, classes and family [8] affect students' psychological well-being. Poor psychological well-being and mental state may affect the positive learning and task performance of the students.

Hence, Ryff et al. [5] had introduced six core dimensions of psychological well-being, specifically: 1) self-acceptance (state of having positive thoughts and feelings about oneself); 2) positive relations with others (ability to engage in warm and trusting relationship with others); 3) autonomy (ability to be independent and coping with social pressure); 4) environmental mastery (ability to adapt, change or create one's environment according to one's needs through physical and mental activities); 5) purpose in life (state of having objectives and goals in life and working towards achieving goal-oriented); and 6) personal growth (continuously growing and developing as oneself). This multidimensional concept of psychological well-being demonstrates the relationships between psychological well-being and life esteem as well as life satisfaction [14], mindfulness [15], physical activity [16-19], and social support [20].

Regarding psychological problems of students in Malaysia, the Ministry of Health in Malaysia has reported that among 400,227 patients with mental illness in 2008, 14.4\% were adolescents. A study conducted at the University Putra Malaysia (UPM) by Zulkefly et al. [21] also found that $47.1 \%$ of UPM students scored low level of psychological well-being indicating that a considerable number of students are at risk for psychological problems. Meanwhile, the National Health and Morbidity Survey conducted by the Ministry of Health in Malaysia in 2011 reported high level of mental health problems among Malaysian adults, with 0.3 million (1.7\%) of them experiencing anxiety disorders and having suicidal thoughts, another 0.3 million (1.8\%) of adults experiencing depression, and 0.2 million (1.1\%) having attempted suicide.

In addition, another study conducted in a Malaysian private medical college showed that $46.2 \%$ of its students suffered emotional disorders [22]. Another study by Fuad et al. [23] conducted at the UPM found that the prevalence rates of student stress, anxiety, and depression among medical students were $16.9 \%, 52 \%$, and $24.4 \%$, respectively. These studies have revealed much about the discouraging psychological state of Malaysian students in tertiary education institutions. Studies conducted in Malaysia have also shown decreased level of psychological well- being among university students in Malaysia [21-23]. Yusoff et al. [24] further reported that academic-related stressors affected students the most.

Meanwhile, regarding the age factor, the results of past research have shown some discrepancies. Creed et al. [25] found no difference in psychological well-being across age groups (young, middle age, and mature-age). However, Ludban et al. [26] demonstrated that there were age differences between students aged 18-23 and students aged 24 years and above. A study conducted by Panahi et al. [27] among postgraduate students at the UPM revealed a significant relationship between age and psychological well-being, denoting that the level of students' psychological well-being increases with age. The authors [27] confirmed also the significant relationship between age and psychological well-being in terms of autonomy, personal growth, and purpose in life. Thus, this study aimed 1 ) to determine the level of psychological well-being among postgraduate students, 2) to assess the correlation between students' demographic profile and their psychological well-being.

\section{MATERIAL AND METHODS}

\section{Sampling and population}

A total of 192 Master's degree students were employed from the various program in the Faculty of Educational Studies from the University Putra Malaysia. Sampling technique using cluster involves dividing the accessible population into groups (clusters) that would be subsequently picked in a simple random manner. The engaging this sampling method in the study is due to no proper access to the entire population as most of the students were on part-time studying schedule.

\section{Measurement}

The questionnaires were divided into two parts, part A contained questions assessing the respondents' demographics and part B contained the 42 items version of Ryff's Psychological Well-Being Scales (PWB). This questionnaire, developed by Ryff et al. [5], is divided into six subscales, self-acceptance (sample item - "When I look at the story of my life, I am pleased with how things have turned out"), positive relationship with others (sample item - "Most people see me as loving and affectionate"), autonomy (sample item - "I am not afraid to voice my opinions, even when they are in opposition to the opinions of most people"), environmental mastery (sample item - "In general, I feel I am in charge of the situation in which I live"), purpose in life (sample item - "I have a sense of direction and purpose in life"), and a sense 
of personal growth (sample item - "I think it is important to have new experiences that challenge how you think about yourself and the world"). Seven items were designed to measure each subscale on a sixpoint Likert scale ranging from 1 (strongly disagree) to 6 (strongly agree). This scale also includes both positive and negative statements to look at the consistency of students' responses for each subscale.

The respondents completed the questionnaire comprising items measured on a six-point Likert scale ranging from 1 (strongly disagree) to 6 (strongly agree). Negative items were reverse coded into positive ones, and the respondents with high scores were deemed to possess high psychological well-being and vice versa.

\section{Data analysis}

The data from research instruments were numerically scored and quantified. The descriptive analysis, such as frequencies, percentages, means, and standard deviations, were employed to determine students' level of psychological well-being. ANOVA was conducted to examine the differences between students' age groups and field of study with their level of psychological well-being. In addition, Spearman's rho correlation analysis was also done to determine the relationship between age and variables.

\section{RESULTS}

\section{Demographics Distribution}

A total of 192 respondents were randomly selected to participate in this study. Among the respondents, the highest percentage of participants were 26 to 30 years old $(43.6 \%)$, followed by 25 years old and younger (41.9\%), 31 to 35 years old (8.1\%), 36 to 40 years old (4.1\%), and 41 years old and above (2.3\%). Regarding gender, female sex consisted of 162 (84.4\%) compared to 30 males (15.6\%). Most of the respondents were self-financed - $111(57.8 \%)$ and sponsored - $81(42,2 \%)$ with the majority in the third semester $-63(32.8 \%)$, followed by the first semester -57 (29.7\%), the second semester - 44 (22.9\%), the fourth semester $-20(10.5 \%)$ and the final fifth semester where there were 8 respondents (4.2\%). Findings demonstrated that 139 (72.4\%) were single and $53(27.6 \%)$ were married. Nevertheless, in this research findings have been concentrated on the age and field of study factors, based on the results that other demographic factors did not show any significant difference in the respondents' psychological well-being.

\section{Descriptive Analysis}

In this study, the level of psychological well-being was calculated by subtracting the minimum score from the maximum score, and it was classified into 3 categories, low (1.40-2.82), moderate (2.83-4.25), and high (4.26-5.67). Concerning the overall level of psychological well-being, the mean level was in the high category $(M=4.39, S D=0.61)$, as shown in Table 1 . Descriptive analysis was used to determine the level and pattern of students' psychological well-being on six of its dimensions (self-acceptance, positive relations with other, autonomy, environmental mastery, purpose in life, and personal growth). The findings indicated high score on the dimension of personal growth $(M=4.84, S D=0.87)$, followed by Purpose in Life $(M=4.57, S D=0.85)$, Positive Relations with others $(M=4.52, S D=0.85)$, Self-acceptance $(M=$ 4.26, $S D=0.78)$, Environmental Mastery $(M=4.23$, $\mathrm{SD}=0.88)$, and Autonomy $(\mathrm{M}=3.97, \mathrm{SD}=0.75)$.

Table 1. Overall Level of Students' Psychological Well-being by Subscale

\begin{tabular}{|l|c|c|}
\hline Subscale & Mean & SD \\
\hline Autonomy & 3.97 & 0.75 \\
\hline Environmental Mastery & 4.23 & 0.88 \\
\hline Personal Growth & 4.84 & 0.87 \\
\hline Positive Relations with Others & 4.52 & 0.85 \\
\hline Purpose in Life & 4.57 & 0.85 \\
\hline Self-acceptance & 4.26 & 0.78 \\
\hline Overall of Psychological Well-being & 4.39 & 0.61 \\
\hline
\end{tabular}

\section{Comparison of Students' Psychological Well-being} by Age

Table 2 displays the difference between students' age groups and their level of psychological well-being. Since the students' age were classified into five groups, 25 and below, 26-30, 31-35, 36-40, 41 and above, ANOVA was conducted to analyze the data. The results indicated that students in different age groups differed significantly in self-acceptance $(F(4$, $192)=3.71, p=.003)$ and overall score of psychological well-being $(F(4,192)=3.18, p=0.50)$.

Tukey HSD test for psychological well-being and its dimensions showed that the mean score for overall level of psychological well-being was significantly higher for students aged 41 and above ( $M=4.83$, $S D=0.58)$. Furthermore, the mean score for the dimension of self-acceptance was also significantly higher for students aged 41 and above ( $M=5$, SD $=0.71$ ). 
Table 2. Level of Psychological Well-being Dimensions across Age Groups

\begin{tabular}{|c|c|c|c|c|c|}
\hline Dimension & Age & $\mathrm{N}$ & Mean & $\mathbf{F}$ & P-value \\
\hline \multirow[t]{5}{*}{ Autonomy } & 25 and below & 77 & 3.95 & 0.11 & .97 \\
\hline & $26-30$ & 84 & 3.97 & & \\
\hline & $31-35$ & 18 & 4.08 & & \\
\hline & $36-40$ & 8 & 3.88 & & \\
\hline & 41 and above & 5 & 3.96 & & \\
\hline \multirow{5}{*}{$\begin{array}{l}\text { Environ- } \\
\text { mental } \\
\text { mastery }\end{array}$} & 25 and below & 77 & 4.35 & 2.43 & .05 \\
\hline & $26-30$ & 84 & 4.02 & & \\
\hline & $31-35$ & 18 & 4.37 & & \\
\hline & $36-40$ & 8 & 4.57 & & \\
\hline & 41 and above & 5 & 4.89 & & \\
\hline \multirow{5}{*}{$\begin{array}{l}\text { Personal } \\
\text { Growth }\end{array}$} & 25 and below & 77 & 4.97 & 1.77 & .14 \\
\hline & $26-30$ & 84 & 4.64 & & \\
\hline & $31-35$ & 18 & 5.04 & & \\
\hline & $36-40$ & 8 & 4.88 & & \\
\hline & 41 and above & 5 & 5.21 & & \\
\hline \multirow{5}{*}{$\begin{array}{l}\text { Positive } \\
\text { relations } \\
\text { with others }\end{array}$} & 25 and below & 77 & 4.68 & 2.37 & .06 \\
\hline & $26-30$ & 84 & 4.31 & & \\
\hline & $31-35$ & 18 & 4.71 & & \\
\hline & $36-40$ & 8 & 4.43 & & \\
\hline & 41 and above & 5 & 4.96 & & \\
\hline \multirow{5}{*}{$\begin{array}{l}\text { Purpose in } \\
\text { life }\end{array}$} & 25 and below & 77 & 4.70 & 1.84 & .12 \\
\hline & $26-30$ & 84 & 4.38 & & \\
\hline & $31-35$ & 18 & 4.72 & & \\
\hline & $36-40$ & 8 & 4.73 & & \\
\hline & 41 and above & 5 & 4.96 & & \\
\hline \multirow{5}{*}{$\begin{array}{l}\text { Self-accep- } \\
\text { tance }\end{array}$} & 25 and below & 77 & 4.38 & 3.17 & .00 \\
\hline & $26-30$ & 84 & 4.02 & & \\
\hline & $31-35$ & 18 & 4.63 & & \\
\hline & $36-40$ & 8 & 4.39 & & \\
\hline & 41 and above & 5 & 5.00 & & \\
\hline \multirow{5}{*}{$\begin{array}{l}\text { Overall psy- } \\
\text { chological } \\
\text { well-being }\end{array}$} & 25 and below & 77 & 4.51 & 3.18 & .01 \\
\hline & $26-30$ & 84 & 4.22 & & \\
\hline & $31-35$ & 18 & 4.59 & & \\
\hline & $36-40$ & 8 & 4.48 & & \\
\hline & 41 and above & 5 & 4.83 & & \\
\hline
\end{tabular}

Comparison of students' psychological well-being by field of study

Table 3 shows the difference between students' field of study and their level of psychological well-being. Students' field of study was classified into 9 different fields of study; Curriculum and Instruction, Educational Administration, Educational Psychology, Educational Technology, Guidance and Counseling, Sports Science, Teaching English as Second Language (TESL), Teaching of Malay as a First Language and Technical and Vocational Education, thus,
ANOVA was conducted to analyze the data in achieving this objective.

Table 3. Differences in Psychological Well-being across students' field of study

\begin{tabular}{|l|c|c|c|c|}
\hline Field of study & N & Mean & F & P \\
\hline Curriculum \& Design & 7 & 3.98 & 2.66 & .01 \\
\hline Administration & 20 & 4.34 & & \\
\hline Psychology & 33 & 4.60 & & \\
\hline Technology & 13 & 4.31 & & \\
\hline Counseling & 12 & 4.19 & & \\
\hline Sport Science & 18 & 4.44 & & \\
\hline $\begin{array}{l}\text { Teaching English as Second } \\
\text { Language }\end{array}$ & 40 & 4.18 & & \\
\hline Teaching Malay as First Language & 7 & 4.86 & & \\
\hline Technical and Vocational & 22 & 4.59 & & \\
\hline
\end{tabular}

Meanwhile, Tukey HSD test for psychological wellbeing and its dimensions showed that for personal growth Educational Psychology students ( $M=5.13$, $\mathrm{SD}=0.92$ ) scored significantly higher than TESL students $(M=4.49, S D=0.91)$. In addition, for positive relations with others, Educational Psychology students $(M=4.81, S D=3.71)$ scored significantly higher than Curriculum and Design students $(M=3.71$, $S D=1.14)$. Furthermore, for the dimension purpose in life, Educational Psychology students ( $M=4.94$, $\mathrm{SD}=0.83$ ) also scored higher than TESL students ( $M$ $=4.26, \mathrm{SD}=0.79$ )

Table 4. Tukey HSD Multiple Comparisons Results

\begin{tabular}{|l|l|l|l|}
\hline $\begin{array}{l}\text { Dependent } \\
\text { Variable }\end{array}$ & Field of Study & $\begin{array}{l}\text { Mean } \\
\text { Difference }\end{array}$ & P-value \\
\hline $\begin{array}{l}\text { Personal } \\
\text { growth }\end{array}$ & $\begin{array}{l}\text { Educational Psychol- } \\
\text { ogy and TESL }\end{array}$ & 0.64 & .04 \\
\hline $\begin{array}{l}\text { Positive } \\
\text { relations with } \\
\text { others }\end{array}$ & $\begin{array}{l}\text { Educational Psychol- } \\
\text { ogy and Curriculum } \\
\text { and Design }\end{array}$ & 1.09 & .04 \\
\hline Purpose in life & $\begin{array}{l}\text { Educational Psychol- } \\
\text { ogy and TESL }\end{array}$ & 0.68 & .02 \\
\hline
\end{tabular}

Correlation of Age Groups and Psychological Wellbeing

In this study, the finding showed a significant difference between students' overall psychological wellbeing $(r=.918, p=.00)$ across different age groups; 25 and below, 26-30, 31-35, 36-40, 41 and above. This shows that students' psychological well-being is affected by age, as shown in Table 5 . 
Table 5. Correlations on Age between Psychological Well being

\begin{tabular}{|l|l|l|l|}
\hline & & & $\mathrm{r}$ \\
\hline \multirow{3}{*}{ Spearman's rho } & \multirow{3}{*}{ Age } & Correlation Coefficient & $.918^{\star \star}$ \\
\cline { 3 - 4 } & & Sig. (2-tailed) & .000 \\
\cline { 3 - 4 } & & $\mathrm{N}$ & 192 \\
\hline
\end{tabular}

** Correlation is significant at the 0.01 level (2-tailed)

* Correlation is significant at the 0.05 level (2-tailed)

\section{DISCUSSION AND CONCLUSION}

\section{Students' Level of Psychological Well-being}

The descriptive analyses indicated that students involved in this study possess rather high levels of overall psychological well-being. Nevertheless, the dimension with the highest mean score was personal growth, followed by purpose in life, positive relations with others, self-acceptance, environmental mastery, and autonomy. In this study context, as postgraduate studies require students to constantly deal with challenges, students are able to experience a higher level of personal growth. In support of this claim, Terenzini et al. [28] reported that students' personal growth increased during the first years of their academic life. Schaefer et al. [29] and Tedeschi et al. [30] also stated that growth is attained by retaining constant adaptability when encountering life crises or traumatic events, as individuals who have encountered traumatic events are also able to be self-governing in difficult situations.

For the second highest dimension, purpose in life, the participant scored the highest on items that indicated agreement with positive items, such as "I have a sense of direction and purposes in life," "I enjoy making plans for the future and working to make them a reality," and "Some people wander aimlessly through life, but I am not one of them." Students are believed to have objectives and goals that need to be fulfilled in their life and that they perceive daily endeavors as meaningful, in the sense that each day should bring them closer to realizing their goals. The level of purpose in life in this study was found to be high. According to Pinquart et al. [31], a decline in purpose in life is more significant in older ages. For this reason, the high level of purpose in life in this study could be caused by the higher number of young adults who participated in this study.

Meanwhile, positive relations with others dimension had high scores on the positive items, such as "I enjoy personal and mutual conversations with family members or friends," "I know that I can trust my friends, and they know they can trust me," and "Most people see me as loving and affectionate." Postgraduate students are perceived as having the ability to engage in warm and trusting relationships with the people in their environment. They are also viewed as affectionate, trustworthy, and empathetic. As most students seek social approval and social support, it is deemed important for them to have positive relations with others. This could be due to cultural influences on students' well-being. Members of collectivistic cultures (i.e., Eastern cultures) are more likely to seek approval and find pleasure in interconnectedness with other people [32]. For this reason, they also prefer shared preference, which portrays the influence of others on individuals' opinions and decision-making. Due to this fact, they are more likely to value positive relations with others compared to people from individualistic cultures (i.e., Western cultures).

The dimension of self-acceptance also had high scores on positive items. Students reported feeling confident about themselves and liking most aspects of their personalities. In addition, they were also more accepting of their past. As the respondents from this study experienced a high level of personal growth, as a result of their academic undertakings, it is understandable that they have accepted their strengths and flaws along the process of developing themselves.

For environmental mastery dimension, high responses were reported for items that indicate students are able to be in charge of their life in terms of managing their responsibilities and adjusting their environment in ways that reflect their liking and personal moods. This finding is in line with the findings of a research conducted by Ryff et al. [33], who demonstrated that the level of environmental mastery is higher among older adults. Since the respondents in this study were students aged 25 and below, it is not surprising that students' environmental mastery was still only moderate.

The overall score for autonomy dimension was the lowest among other dimensions. Even though the responses with high scores were related to confidence and the ability to self-govern one's judgments of their opinions, the responses pertaining to their opinions and decision making that correspond with those of other people were also quite high. This indicated that students involved in this study were self-governing in their opinions and decision-making. Nonetheless, they also tended to worry about the evaluation of other people, and this affected their sense of autonomy. This could be due to the fact that postgraduate students are mostly on their own in their academic endeavors; however, they are also aware of the importance of the people in their academic surround- 
ings who they can rely on for social support. A study by lyengar et al. [32] demonstrated that individuals in some cultures (particularly the Eastern cultures) were inclined to prefer decisions that are made for them by their significant others. As the respondents of this study were from an Eastern culture, this explains the low level of autonomy and high level of positive relations with others.

Overall, students' psychological well-being demonstrated higher levels of personal growth, purpose in life, and positive relations with others and lower levels of self-acceptance, environmental mastery, and autonomy. This finding is in accordance with the findings by Ryff et al. [34], who demonstrated that individuals from the Eastern culture showed higher levels of positive relations with others and individuals from the Western culture showed higher levels of self-acceptance and autonomy. This finding is also in line with the findings from Ryff et al. [5], who revealed that students from Educational Studies had high levels of personal growth and positive relations with others.

\section{Demographic factors affecting psychological well- being}

The demographic factor in this study was age. Significant differences have been observed between students' overall psychological well-being and selfacceptance by age. The results showed that students who are 25 years old and below possessed better overall psychological well-being and self-acceptance compared to students who are 26 to 30 years old. In this study, students aged 25 years old and below reported significantly higher level of self-acceptance compared to students aged between 26 to 30 years old. This finding contradicts the results of Ryff et al. [34], who found no difference in self-acceptance across age groups.

In addition, in terms of different field of study, there were also significant differences in students' overall psychological well-being, personal growth, positive relations with others and purpose in life. Educational Psychology students seemed to have significantly better personal growth and purpose in life than TESL students. Results also showed that Educational Psychology students have better positive relations with others than Curriculum and Design students. These findings depicted that Educational Psychology students may have experienced meaningful learning experiences in comparison to TESL and Curriculum and Design students. Positive and meaningful learning experiences would then contribute to personal growth and good rapport with their classmates as well as the people in their environment, thus resulting in better psychological well-being.

\section{REFERENCES}

1. Ryan, R.M. and E.L. Deci, Self-determination theory and the role of basic psychological needs in personality and the organization of behavior. Handbook of personality: Theory and research, 2008, 3: 654-78.

2. Diener, E., et al. Subjective well-being: Three decades of progress. Psychological Bulletin, 1999, 125(2): 276-302.

3. Diener, E. Subjective well-being, in The science of well-being 2009, Springer. 11-58.

4. Chekola, M. The concept of happiness (Unpublished doctoral dissertation). University of Michigan, 1974.

5. Ryff, C.D. Happiness is everything, or is it? Explorations on the meaning of psychological well-being. Journal of Personality and Social Psychology, 1989, 57(6): 1069-81.

6. Yang, Y.-T.T. Stress, coping, and psychological well-being: Comparison among American and Asian international graduate students from Taiwan, China, and South Korea, 2010.

7. Lovitts, B.E. Being a good course taker is not enough: A theoretical perspective on the transition to independent research. Studies in Higher Education, 2005, 30(2): 137-154.

8. Abiddin, N.Z. and A. Ismail. Attrition and completion issues in postgraduate studies for student development. International Review of Social Sciences and Humanities, 2011, 1(1): 15-29.

9. Lessing, A. and S. Schulze. Postgraduate supervision and academic support: students' perceptions. South African Journal of Higher Education, 2002, 16(2): 139-149.

10. Sherina, M., L. Rampal, and N. Kaneson. Psychological stress among undergraduate medical students. Medical Journal of Malaysia, 2004, 59(2): 207-211.

11. Regehr, C., D. Glancy, and A. Pitts. Interventions to reduce stress in university students: A review and meta-analysis. Journal of affective disorders, 2013, 148(1): 1-11.

12. Byrd, D.R. and K.J. McKinney. Individual, interpersonal, and institutional level factors associated with the mental health of college students. Journal of American College Health, 2012, 60(3): 185-193.

13. Lange, C. and M. Byrd. The relationship between perceptions of financial distress and feelings of psychological well-being in New Zealand university students. International Journal of Adolescence and Youth, 1998, 7(3): 193-209.

14. Armsden, G.C. and M.T. Greenberg. The inventory of parent and peer attachment: Individual differences and their relationship to psychological well-being in adolescence. Journal of youth and adolescence, 1987, 16(5): 427-454.

15. Brown, K.W. and R.M. Ryan. The benefits of being present: mindfulness and its role in psychological well-being. Journal of Personality and Social Psychology, 2003, 84(4): 822-831.

16. Biddle, S.J. and M. Asare. Physical activity and mental health in children and adolescents: a review of reviews. British journal of sports medicine, 2011: 34-42.

17. Biddle, S.J., K. Fox, and S. Boutcher. Physical activity and psychological well-being 2003: Routledge.

18. Kargarfard, M., et al. Efficacy of massage on muscle soreness, perceived recovery, physiological restoration and physical performance in male bodybuilders. Journal of Sports Sciences, 2016, 34(10): 959-965.

19. Kargarfard, M., et al. Effects of polluted air on cardiovascular and hematological parameters after progressive maximal aerobic exercise. Lung, 2015, 193(2): 275-281.

20. Lakey, B. and E. Orehek. Relational regulation theory: a new approach to explain the link between perceived social support and mental health. Psychological Review, 2011, 118(3): 482-90. 
21. Zulkefly, N.S. and R. Baharudin. Using the 12-item General Health Questionnaire (GHQ-12) to assess the psychological health of Malaysian college students. Global Journal of Health Science, 2010, 2(1): 73-80.

22. Zaid, Z., S. Chan, and J. Ho. Emotional disorders among medical students in a Malaysian private medical school. Singapore Medical Journal, 2007, 48(10): 895-9.

23. Fuad, M.D., et al. Prevalence and risk factors of stress, anxiety and depression among medical students of a private medical university in Malaysia. Education in Medicine Journal, 2015, 7(2): 44-52.

24. Yusoff, M.S.B., A.F.A. Rahim, and M.J. Yaacob. Prevalence and sources of stress among Universiti Sains Malaysia medical students. Malaysian Journal of Medical Sciences, 2010, 17(1): 30-37.

25. Creed, P.A. and T. Watson. Age, gender, psychological wellbeing and the impact of losing the latent and manifest benefits of employment in unemployed people. Australian Journal of Psychology, 2003, 55(2): 95-103.

26. Ludban, M. Psychological Well-Being of College Students. Undergraduate Research Journal for the Human Sciences, 2015, 14(1): 47-58.
27. Panahi, S., A.S.B.M. Yunus, and S.B. Roslan. Correlates of Psychological Well-being amongst Graduate Students in Malaysia. Life Science Journal, 2013, 10(3): 1859-70.

28. Terenzini, P.T., C. Theophilides, and W.G. Lorang. Influences on students' perceptions of their personal development during the first three years of college. Research in higher education, 1984, 21(2): 178-194.

29. Schaefer, J.A. and R.H. Moos. Life crises and personal growth, 1992.

30. Tedeschi, R.G. and L.G. Calhoun.The Posttraumatic Growth Inventory: Measuring the positive legacy of trauma. Journal of traumatic stress, 1996, 9(3): 455-471.

31. Pinquart, $M$. Creating and maintaining purpose in life in old age: A meta-analysis. Ageing international, 2002,. 27(2): 90-114.

32. lyengar, S.S. and M.R. Lepper. Rethinking the value of choice: a cultural perspective on intrinsic motivation. Journal of personality and social psychology, 1999, 76(3): 349-361.

33. Ryff, C.D. and B.H. Singer. Know thyself and become what you are: A eudaimonic approach to psychological well-being. Journal of happiness studies, 2008, 9(1): 13-39.

34. Ryff, C.D. and C.L.M. Keyes. The structure of psychological well-being revisited. Journal of Personality and Social Psychology, 1995, 69(4): 719-727. 